\title{
A cultura da medicalização de crianças e adolescentes: dimensões possíveis
}

\author{
Damon B. S. Andrade
}

\section{RESUMO}

A proposta deste trabalho almeja analisar e discutir a cultura da medicalização de crianças e adolescentes no Brasil intuindo uma compreensão acerca da relação instituição de ensino $x$ alunado. Também obtém destaque o aumento exponencial de encaminhamentos de crianças vítimas de queixa escolar a profissionais terceiros. A partir do estudo de documentos e da leitura especializada, depara-se com a necessidade de desvelar aspectos ideológicos que demarcam no tempo e no espaço - a produção de um saber científico que naturaliza práticas e relações sociais. Surge então a massificação dos psicodiagnósticos e psicofármacos. Tomando como referencial as teorias que consubstanciam a psicologia educacional crítica e demais documentos que ajudam a compreender as relações de poder de maneira microcósmica - e não estática - o trabalho busca refletir acerca do que fazer de grande parte relevante dos profissionais atuantes no ambiente educacional. Pertence também ao universo dessa produção, uma visão crítica aos discursos de um sujeito do suposto saber especializado e identificar as explícitas contradições.

Palavras-chave: Cultura da medicalização; Medicalização de crianças e adolescentes; Instituições de ensino.

\section{INTRODUÇÃO}

O artigo visa a se debruçar sobre subjetividades especiais num contexto específico. Especial por se tratar da grande maioria dos futuros representantes da população brasileira: as crianças e adolescentes. Eis a necessidade de como a educação pode ser repensada em nosso país, quiçá, utilizando-a como uma ferramenta que coopere incisivamente no desenvolvimento de uma sensibilidade ética. Um dos mecanismos mais significativos para tal empreitada são, indubitavelmente, as instituições de ensino: as escolas.

Conhecer as realidades atuais - não de maneira neutra - dando a devida atenção as pessoas que foram e que continuam sendo excluídas de maneiras diversas (e perversas),desvela um problema 
que demanda ações diversas. Uma das formas de "produção" dessa exclusão situa-se na precarização da educação. Um processo de massificação, de despotencialização, manejado por uma ideologia arraigada no sistema econômico hodierno que atua como verdadeira indústria de reificação do ser humano (PATTO, 2008). O objetivo desse trabalho não contempla a vilanização de personagens, nem uma desmesurada tentativa de culpabilizar o aluno, o professor, as políticas públicas. Seu escopo busca compreender como funciona esse imbricado fenômeno social, suscitando novas formas de reflexões e intervenções e, demonstrar como o regime educacional está veementemente influenciado por uma cultura da medicalização de crianças e adolescentes.

Individualizar, personificando "o problema" na figura do aluno seria a maneira mais salutar para lidar com o processo de escolarização? De que forma poderíamos atuar atendendo a demanda dos docentes e dos demais envolvidos nesse cenário sem a orientação do trabalho regido pela culpa? O desafio, segundo Machado (2007),

[...] é conseguir fortalecer esse campo enfraquecido no qual tem dominado esse tipo de funcionamento. Isso exige que criemos dispositivos que permitam fazer novas conexões, valorizar produções desconsideradas, agir de maneira que novas possibilidades contaminem esse campo de relações (MACHADO, 2007, p. 123).

A reflexão acerca desse fenômeno se justifica ao constatar índices recordes de vendagem e produção de psicofármacos. Um movimento atento a todo e qualquer comportamento que destoe da norma dominante. Focar o problema de maneira biologizante fortalece a máxima que propõe uma massificação de terapêuticas medicamentosas. Fenômeno esse que gera uma espécie de docilização em massa, produzindo uma poderosa ideologia que subsidia oligopólios por trás de uma artificialização da subjetividade (ABREU, 2006).

Moyses e Collares (2011a) fazem coro ao movimento que contesta o processo de medicalização desenfreado e o propósito de tal empreitada:

[...] A comprovação de que um conjunto de sinais, sintomas, alterações no exame físico e em exames laboratoriais constitui uma doença passa por outros caminhos, dentro da racionalidade médica. É este um dos grandes equívocos nessa área. Não tem sentido buscar a causa genética de algo tão mal conceituado, mal definido, mal diagnosticado/rotulado... talvez seja o caso de perguntarmos a quê servem tantos pesquisadores de renome, mantendo e amplificando no ideário da vida cotidiana que os seres humanos são homogêneos, obedecendo a um único padrão de comportamento e de pensamento, e que a pluralidade e a diversidade são doenças. (MOYSES; COLLARES, 2011a, p. 88). 
Basta atentar à conduta de alguns profissionais para que transpareça um processo de alienação e reificação. Alienação quando tange a naturalização de atos e ações que de natural (normal) nada possuem. Psicodiagnosticar uma criança de seis anos, por exemplo, com um espectro de problemas: TDAH, dislexia, transtorno de conduta antissocial, dentre outros não poderia ser considerado um caso de incoerência e má utilização de sua própria práxis laboral? (ANGELLUCCI, 2007) Reificação quando o sujeito deixa de ser reconhecido como tal e é adjetivado "portador de": TDAH, depressão, borderline, dentre tantos outros. A percepção sobre o mesmo é abruptamente "adaptada" para lidar com o indivíduo dotado de algum problema. Considerando os aspectos levantados, a relevância desse trabalho justifica-se devido o caráter emergencial em lidar com as questões referidas. Principalmente a respeito do aumento exponencial nos encaminhamentos e na vendagem de psicofármacos (MOYSES;COLLARES. 2011b).

O processo de escolarização, nos moldes atuais, tem propiciado uma relação multiprofissional: psicólogos, neurologistas, psiquiatras, dentre outros. O surgimento dessas novas relações beneficia a todos os envolvidos? As crianças e adolescentes estão se empoderando dessas relações a fim de tornarem-se cidadãos éticos, com autonomia e dignidade? Dessas relações têm eclodido diversas produções de saberes atrelados a um biologicismo, transformando possíveis casos de discussões acerca das relações sociopolíticas em explicações de cunho biofisiológico. Moyses e Collares (2011) alegam que

Nas sociedades ocidentais, é crescente o deslocamento de problemas inerentes à vida para o campo médico, com a transformação de questões coletivas, de ordem social e política, em questões individuais biológicas. Tratar questões sociais como se fossem biológicas iguala o mundo da vida ao mundo da natureza. Isentam-se de responsabilidades todas as instâncias de poder, em cujas entranhas são gerados e perpetuados tais problemas. No mundo da natureza, os processos e fenômenos obedecem a leis naturais. A medicalização naturaliza a vida, todos os processos e relações socialmente construídos e, em decorrência, desconstrói direitos humanos, uma construção histórica do mundo da vida. (MOYSES; COLLARES, 2011a, p. 72).

A metodologia utilizada para produção do trabalho: revisão de literatura; mostrou ser a mais adequada devido à necessidade de analisar as questões atreladas à cultura da medicalização das crianças e adolescentes em âmbito educacional e o quefazer da Psicologia no contexto referido. Categorizou-se o material encontrado - vide produções literárias, artigos científicos das bases de dados: Scielo e BVS psi - numa tabela de argumentos, destacando informações que deram corpo as demandas e as problematizações expostas. 
A fim de contemplar tal empreitada, o trabalho pretende, na primeira sessão, adentrar no sistema educacional brasileiro. Compreender, através de uma história delimitada no tempo e no espaço, a hodierna conjuntura que propiciou a eclosão dos encaminhamentos cuja consequência é a produção de psicodiagnósticos em sua grande maioria arbitrários. O próximo passo do trabalho direciona sua lente investigativa à desconstrução e reconstrução de subjetividades (crianças e adolescentes) sendo psicodiagnosticadas e o poder desse ato sobre as mesmas. As consequências impingidas do problema do estigma dos alunos-pacientes e os atores envolvidos no processo de medicalização.

\section{EDUCAÇÃO E SOCIEDADE: DIGRESSÕES NECESSÁRIAS}

A fim de tentar elucidar e se situar no complexo cenário que envolve os processos educacionais e a relação deles com o social, Gallo (2008) comenta acerca de uma categorização feita pelo VeigaNeto, que identifica, na produção de Foucault, "três domínios": o do ser-saber; o do ser-poder; e o do ser-consigo: "Penso que cada um desses domínios pode ter implicações interessantes no pensamento educacional contemporâneo, se quisermos investir num pensamento aberto, produtivo, criativo, não afeito a verdades prontas e definitivas." (GALLO, 2008, p. 256). Acerca do primeiro domínio elencado pelo autor, educação e ser saber, há a descrição de um movimento necessário para que a pedagogia adquirisse status científico. Os saberes se aproximando do real e o homem tornando-se alvo de representação das ciências humanas. Sugere o autor que uma Filosofia da Educação de inspiração foucaultiana "[...] pode revelar a historicidade dos conhecimentos educacionais, para além de qualquer apelo universal, auxiliando a desvendar os mecanismos disciplinares e de tecnologia de saber que permitiriam a conformação da escola moderna tal como a conhecemos, fornecendo elementos para que compreendamos sua crise." (GALLO, 2008, p. 257). Sugestão consonante ao objetivo deste trabalho que, a guisa de uma pesquisa bibliográfica, almeja o desvelar de práticas ideológicas mantenedoras, alicerçando as crises conjunturais que assolam o ambiente educacional.

O segundo domínio: educação e ser poder; o enfoque é colocado nas tecnologias disciplinares como uma maneira de introjetar a dominação nos corpos. Só que se refere a uma escala macro, a nível populacional. Ou seja, o exercício do biopoder exercerá a governabilidade dos povos. Controles de endemias, epidemias, de natalidade, ações governamentais que implicariam na subsistência (ou não) de populações marginalizadas são exemplos de exercício do biopoder sob a égide da biopolítica. A esfera do "fazer viver", ou "deixar morrer". O saber de uma ciência psicológica produtora de psicodiagnósticos arbitrários; de uma psiquiatria que reduz sua riqueza 
conceitual e laboral a produtores de receituários à psicofármacos a fim de produzir verdades sobre os corpos, não seria uma maneira escusa de exercer o biopoder? Eis mais um motivo para que Gallo atente à uma análise do poder que

[...] permite compreender as diferentes conformações históricas das práticas educativas e de suas instituições. Desvendando as relações de poder no âmbito das práticas educativas, podemos investir na criação de novas relações, de novas possibilidades de ser e de construção subjetiva, não necessariamente moldadas pelos cânones instituídos. (GALLO, 2008, p. 257).

O terceiro domínio: educação e ser-consigo; refere-se a um convite de Foucault para que façamos uma auto avaliação a fim de averiguarmos aquilo que estamos fazendo conosco. Em se tratando do educador, mais relevante ainda, pois, analisar suas próprias condutas implicará numa avaliação de que forma se afeta os educandos. O pensamento ulterior nos permite acreditar que o processo de "escolarização" dos docentes encontra-se fragilizado a ponto de não atingir os objetivos esperados: a formação com viés emancipatório do outro. O docente, teoricamente, é a ferramenta fundamental de um processo de conscientização social, moral e ética. Mas na prática, o embrutecimento tem sido generalizado.

Pensando com Foucault, o educador precisa adestrar-se a si mesmo, construir-se como educador, para que possa educar, isto é, preparar ao outro para que adestre-se a si mesmo. [...] o educador precisa emancipar-se a si mesmo, para que sua atividade docente possa ser um ato de emancipação e não de embrutecimento. (GALLO, 2008, p. 259).

Intuindo o desvelar de constructos ideológicos que fazem com que a biologização das condutas de crianças e adolescentes tenham tanto poder no contexto atual, será realizado um recorte de alguns momentos históricos relevantes que influenciaram a ordenação da sociedade. A relevância desse retorno contempla um exercício epistemológico necessário a fim de compreender os aspectos originários de movimentos sociopolíticos datados, responsáveis pela atual estrutura educacional brasileira.

Focar-se-á especialmente nas questões relacionadas a educação, direcionando o olhar para a produção do fracasso escolar, um contexto repleto de teorias das mais variadas. Dentre elas, destacam-se algumas por sua relevância e pregnância na sociedade brasileira: teorias racistas, hereditárias e carência cultural. Importante salientar que esse trabalho não contemplará toda a riqueza discursiva das teorias cientificas que, dentre tantas consequências, intuíram uma explicação do fracasso escolar. Logo, a atenção se direcionará para os aspectos relacionais entre 
o estabelecimento de saberes produzidos e delimitados, no tempo e no espaço, e suas reverberações no contexto escolar.

Pensar em movimentos científico-culturais que ocorreram na Europa e em outras partes do mundo, nos remete diretamente as ações perpetradas no Brasil. Segundo Patto (2008), se a primeira vista parecer irrelevante associar teorias científicas do século XIX, desenvolvidas na Europa, com as disparidades de nível em se tratando de rendimento escolar no Brasil, basta recordar

[...] que os intelectuais brasileiros começaram a voltar-se para as questões da escola e da aprendizagem escolar num momento em que o país vivia mergulhado num colonialismo cultural que fazia de nossa cultura, segundo uma expressão usada por Cunha (1981), uma "cultura reflexa", sobretudo sob a influência da filosofia e da ciência francesa. (PATTO, 2008, p. 53).

As explicações de cunho racista tornaram-se tradutoras das desigualdades sociais e influenciaram o mundo de tal forma que serviu como justificativa para a invasão de diversas potências as regiões africanas e asiáticas, culminando no período imperialista, responsável pelo sofrimento de grande contingente populacional vide a primeira guerra mundial. A lógica não destoava do que já ocorrera no início da revolução burguesa e industrial, o saber dito científico legalizando as práticas que potencializavam os lucros, a produtividade, mas que, em contrapartida, era uma indústria de segregação e exploração. A fim de manter imaculada a ideia de igualdade, irmandade e fraternidade, os representantes do racionalismo: cientistas, filósofos e ademais, praticavam um cientificismo ingênuo (Poliakov, 1974), sem provas contundentes, mas utilizavam do seu prestígio a fim de propagar tais ideias contraditórias. Uma resignação e a naturalização de algo que foi construído sócio historicamente.

No bojo desses acontecimentos, surgiu o darwinismo social, uma deturpação da teoria evolucionista de Darwin que acaba por reafirmar as teorias racistas. Patto (2008) denuncia que [...] as teorias racistas encontraram na teoria evolucionista elementos para sua reafirmação. $A$ teoria de Darwin (1809-1882) foi assimilada e transformada pelos intelectuais da burguesia na formulação do darwinismo social e colocada a serviço da justificação da reconstrução da hierarquia social que se operara no interior da nova ordem social. [...] A transposição de suas ideias para o universo social resulta numa biologização mistificadora da vida em sociedade e justificadora da exploração e da opressão pelas classes dominantes dos países colonialistas, tanto dentro como fora de suas fronteiras. (PATTO, 2008, p. 57). 
Hobsbawn (1982, p. 273), também num movimento de resistência, alega que "O "darwinismo social" e antropologia racista pertencem não à ciência do século XIX, mas à sua política".

Mesmo algo tão revolucionário e clarificador como as ideias de Darwin, podem ser utilizadas como ferramentas de segregação e naturalização do desnatural (isonomia dos seres humanos); uma tentativa de justificar o racismo e as desigualdades sociais; um estratagema político. $O$ arremate era algo natural e corriqueiro para aqueles que defendiam as teorias racistas, visto que a ciência nunca foi capaz de comprovar tais diferenças.

Francis Galton (1822-1891), cientista renomado, foi o primeiro a, segundo Patto (2008), "fazer o transplante dos princípios evolucionistas de variação, seleção e adaptação para o estudo das capacidades humanas". De acordo com ele, no seu primeiro livro "hereditary genius": "Proponho mostrar neste livro que as habilidades naturais do homem são herdadas sob exatamente as mesmas limitações das formas e características físicas de todo o mundo orgânico. "” (GALTON, 1869, p.1, tradução nossa). Está instituído um processo de triagem. Os considerados mais inteligentes são aqueles que obtêm melhores resultados em testes que auferem acuidade visual, motora, perceptual. Galton acreditava que as capacidades intelectuais estavam fortemente relacionadas com as capacidades perceptuais. Tais pesquisas fomentaram estudos diversos a fim de comprovar o caráter herdado da inteligência e maneiras de categorizar os examinandos. Se refletirmos que os testes eram produzidos pela elite intelectual e que muitas vezes estavam repletos de especificidades conceituais que a classe referida possuía maiores facilidades de acesso, tornava-se óbvio quem seriam os melhores avaliados.

Atentar para as influências pregressas torna-se mister para compreender os aspectos originários das explicações em torno da aprendizagem escolar. Estas, articulando-se com a confluência de duas vertentes: das ciências biológicas e da medicina do século XIX, recebem forte influência da visão organicista das aptidões humanas, carregada de pressupostos racistas e elitistas. $E$, de acordo com Patto (2008),

[...] da Psicologia e da Pedagogia da passagem do século, herda uma concepção menos heredológica da conduta humana - isto é, um pouco mais atentas às influências ambientais - e mais comprometida com os ideais liberais democráticos. A ambiguidade imposta por essa dupla origem será uma característica do discurso sobre os problemas de aprendizagem escolar e da própria política educacional, nele baseada, nos países capitalistas no decorrer de todo o século XX (PATTO, 2008, p.64).

\footnotetext{
${ }^{1}$ I propose to show in this book that a man's natural abilities are derived by inheritance, under exactly the same limitations as are the form and physical features of the whole organic world.
} 
Não é difícil observar, mesmo porque é de maneira - muitas vezes - explícita que acontece: um docente culpabilizando uma organização familiar desestruturada, sem condições socioeconômicas para dar suporte ao aluno. E esse discurso é corroborado por pesquisas que carecem de uma autocrítica acerca de sua metodologia. Muitas vezes utilizam métodos que suscetibilizam uma maior adaptabilidade da classe dominante, pois adéquam-se ao que a pesquisa, em si, considera como modelo ideal de conduta e resposta. Enquanto que os menos favorecidos socioeconomicamente poderiam sentir-se inibidos diante de um "cientista", sujeito que representa o domínio do saber. Muitos desses estudos fazem comparações indevidas de duas realidades distintas. Tornam o ambiente uma dimensão acrítica, contagiada de

[...] uma visão biologizada da vida social e com uma visão etnocêntrica de cultura: de um lado o ambiente é praticamente reduzido a estimulação sensorial proveniente do meio físico; de outro, valores, crenças, normas, hábitos e habilidades tidos como típicos das classes dominantes são considerados como os mais adequados à promoção de um desenvolvimento psicológico sadio (PATTO, 2008, p.73-74).

A teoria da carência cultural traduz muitos dos estereótipos e preconceitos sociais acerca dos pobres. A sociedade brasileira, marcada por características em que se torna difícil desassociar a dialética incluído-excluído, representa um pólo de manutenção dessas práticas que, quando não de maneira consciente, contribuem para a manutenção de um sistema que necessita do "carente", "inculto", "oriundo de família desajustada". O morador de favela apresenta estrutura psicológica/comportamental "favelizada". O indivíduo não aprende por que é representante de uma família humilde, ou os projetos pedagógicos utilizados são produzidos através de influencias destoantes, de uma realidade que diverge da sua? Algumas pesquisas que endossam as tentativas de justificar o fracasso escolar estabelecendo relação causal com a condição socioeconômica não conseguem desvelar o imbricado contexto em que subjaz as políticas educacionais e, muitas vezes, o que está envolto no não aprendizado. Segundo Patto (1997),

A "teoria" da carência cultural retomou a explicação da "marginalidade" social e legal nos termos biopsicológicos que vieram no bojo do movimento escolanovista. Gerada nos anos 60 nos Estados Unidos da América, no interior do movimento por direitos civis das chamadas minorias raciais, ela é portadora de todos os estereótipos e preconceitos sociais a respeito dos pobres e continua marcando presença nos meios em que se planeja e se faz a educação escolar primária no Brasil. Tomada como base de medidas administrativas e pedagógicas que visam à busca de saídas técnicas para o beco no qual se encontra a educação pública elementar, ela só tem contribuído para o aprofundamento da má qualidade da escola que se oferece ao povo, na medida que justifica um barateamento do ensino que acaba realizando a profecia segundo a qual os pobres não têm capacidade suficiente para o sucesso escolar. (PATTO, 1997). 
Essas relações de poder são tratadas pelo Alfredo Veiga Neto (2008) de maneira afim com as ideias de Foucault, que destoa de uma grande vertente que potencializa e coisifica o poder, tornando-o soberano, algoz daqueles que não gozam do mesmo. A ideia de "poder" como energia, que perpassa todas as esferas sociais, exercendo micro manifestações de embates parece salutar à medida que o objeto de estudo se transforma, permitindo que a análise contemple dimensões inatingíveis até então. Rago e Veiga-Neto (2008) alegam, que

Deslocar o conceito de poder de coisa para relação, Foucault prefere não centrar a discussão sobre "o que é o poder", mas sobre "como ele funciona", "como age o poder", o que equivale a dizer que a questão não é ir atrás de um princípio fundamental e geral em que se assentaria o poder, mas examinar os agenciamentos em que se cruzam as práticas (RAGO; VEIGA-NETO, 2008, p. 24).

Prosseguem argumentando que,

[...] ao fazermos a distinção forte entre violência e poder, conseguiremos enxergar coisas que, de outra maneira permaneceria à sombra; Isso será assim porque tal discrição não apenas permite descer ao nível microfísico das experiências escolares, mas, também e principalmente, porque tal distinção, ao mudar o registro discursivo de uma prática, muda a própria visibilidade dessa prática (RAGO;VEIGA-NETO, 2008, p. 32).

O capítulo subsequente adentrará na microfísica dessas relações a fim de tentar compreender as consequências de tais ações, principalmente nas crianças e adolescentes.

\section{A CULTURA DA MEDICALIZAÇÃO DE CRIANÇAS E ADOLESCENTES VIA MODELO EDUCACIONAL: CONSEQUÊNCIAS ORIGINÁRIAS}

O Transtorno de Déficit de Atenção/Hiperatividade (TDA/H) será utilizado como a metonímia do processo de medicalização. A escolha deste transtorno deve-se a sua hodierna relevância e exponencial aumento, seja de psicodiagnósticos, seja em nível de intervenção medicamentosa, culminando em recordes de vendagem de medicamentos psicofármacos utilizados a fim de atenuar os sintomas que se supõem oriundos do transtorno. Segundo Rohde et al. (2004), o TDAH é o transtorno psiquiátrico mais comum na infância, cerca de $4 \%$ a $10 \%$ das crianças sofrem do mesmo. Ainda segundo Rohde et al. (2000):

As primeiras referências aos transtornos hipercinéticos na literatura médica apareceram no meio do século XIX. Entretanto, sua nomenclatura vem sofrendo alterações contínuas. Na década de 40, surgiu a 
designação "lesão cerebral mínima", que, já em 1962, foi modificada para "disfunção cerebral mínima", reconhecendo-se que as alterações características da síndrome relacionam-se mais a disfunções em vias nervosas do que propriamente a lesões nas mesmas (ROHDE, 2004, p. 7).

Somente em 1994 que, através do DSM-IV, ocorrera à mudança de nomenclatura para "Transtorno de Déficit de Atenção/Hiperatividade".

Os critérios diagnósticos para o TDAH, de acordo com o Manual Diagnóstico e Estatístico de Transtornos Mentais (APA, 2014, p. 59-60), estão dispostos no quadro abaixo:

\section{QUADRO 1: Critérios Diagnósticos para Transtorno de Déficit de Atenção/Hiperatividade}

A. Um padrão persistente de desatenção e/ou hiperatividade-impulsividade que interfere
no funcionamento e no desenvolvimento, conforme caracterizado por (1) e/ou (2):
1. Desatenção:Seis (ou mais) dos seguintes sintomas persistem por pelo menos
seis meses em um grau que é inconsistente com o nível do desenvolvimento e têm
impacto negativo diretamente nas atividades sociais e acadêmicas/profissionais:
Nota: Os sintomas não são apenas uma manifestação de comportamento opositor,
desafio, hostilidade ou dificuldade para compreender tarefas ou instruções. Para
adolescentes mais velhos e adultos (17 anos ou mais), pelo menos cinco sintomas são
necessários.
a. frequentemente deixa de prestar atenção a detalhes ou comete erros por descuido
em atividades escolares, de trabalho ou outras;
b. com frequência tem dificuldades para manter a atenção em tarefas ou atividades
lúdicas
c. com frequência parece não escutar quando lhe dirigem a palavra;
d. com frequência não segue instruções e não termina seus deveres escolares, tarefas
domésticas ou deveres profissionais (não devido a comportamento de oposição ou
incapacidade de compreender instruções);
e. com frequência tem dificuldade para organizar tarefas e atividades;
f. com frequência evita, antipatiza ou reluta a envolver-se em tarefas que exijam esforço
mental constante;
g. com frequência perde coisas necessárias para tarefas ou atividades;
persistem por pelo menos seis meses em um grau que é inconsistente com o nível do


desenvolvimento e têm impacto negativo diretamente nas atividades sociais e acadêmicas/profissionais:

Nota: Os sintomas não são apenas uma manifestação de comportamento opositor, desafio, hostilidade ou dificuldade para compreender tarefas ou instruções. Para adolescentes mais velhos e adultos (17 anos ou mais), pelo menos cinco sintomas são necessários.

a. Frequentemente remexe ou batuca as mãos ou os pés ou se contorce na cadeira.

b. Frequentemente levanta da cadeira em situações em que se espera que permaneça sentado (p. ex., sai do seu lugar em sala de aula, no escritório ou em outro local de trabalho ou em outras situações que exijam que se permaneça em um mesmo lugar).

c. Frequentemente corre ou sobe nas coisas em situações em que isso é inapropriado. (Nota: Em adolescentes ou adultos, pode se limitar a sensações de inquietude.)

d. Com frequência é incapaz de brincar ou se envolver em atividades de lazer calmamente.

e. Com frequência "não para", agindo como se estivesse "com o motor ligado" (p. ex., não consegue ou se sente desconfortável em ficar parado por muito tempo, como em restaurantes, reuniões; outros podem ver o indivíduo como inquieto ou difícil de acompanhar).

f. Frequentemente fala demais.

g. Frequentemente deixa escapar uma resposta antes que a pergunta tenha sido concluída (p. ex., termina frases dos outros, não consegue aguardar a vez de falar).

h. Frequentemente tem dificuldade para esperar a sua vez (p. ex., aguardar em uma fila).

i. Frequentemente interrompe ou se intromete (p. ex., mete-se nas conversas, jogos ou atividades; pode começar a usar as coisas de outras pessoas sem pedir ou receber permissão; para adolescentes e adultos, pode intrometer-se em ou assumir o controle sobre o que outros estão fazendo.)

B. Vários sintomas de desatenção ou hiperatividade-impulsividade estavam presentes antes dos 12 anos de idade.

C. Vários sintomas de desatenção ou hiperatividade-impulsividade estão presentes em dois ou mais ambientes (p. ex., em casa, na escola, no trabalho; com amigos ou parentes; em outras atividades).

D. Há evidências claras de que os sintomas interferem no funcionamento social, acadêmico ou profissional ou de que reduzem sua qualidade.

E. Os sintomas não ocorrem exclusivamente durante o curso de esquizofrenia ou outro transtorno psicótico e não são mais bem explicados por outro transtorno mental (p. ex., 
transtorno do humor, transtorno de ansiedade, transtorno dissociativo, transtorno da personalidade, intoxicação ou abstinência de substância).

Determinar o subtipo:

314.01 (F90.2)Apresentação combinada: Se tanto o Critério A1 (desatenção) quanto o Critério A2 (hiperatividade-impulsividade) são preenchidos nos últimos 6 meses.

314.00 (F90.0) Apresentação predominantemente desatenta: Se o Critério A1 (desatenção) é preenchido, mas o Critério A2 (hiperatividade-impulsividade) não é preenchido nos últimos 6 meses.

314.01 (F90.1) Apresentação predominantemente hiperativa/impulsiva: Se o Critério A2 (hiperatividade-impulsividade) é preenchido, e o Critério A1 (desatenção) não é preenchido nos últimos 6 meses.

Especificar se:

Em remissão parcial: Quando todos os critérios foram preenchidos no passado, nem todos os critérios foram preenchidos nos últimos 6 meses, e os sintomas ainda resultam em prejuízo no funcionamento social, acadêmico ou profissional.

Especificar a gravidade atual:

Leve: Poucos sintomas, se algum, estão presentes além daqueles necessários para fazer o diagnóstico, e os sintomas resultam em não mais do que pequenos prejuízos no funcionamento social ou profissional.

Moderada: Sintomas ou prejuízo funcional entre "leve" e "grave" estão presentes.

Grave: Muitos sintomas além daqueles necessários para fazer o diagnóstico estão presentes, ou vários sintomas particularmente graves estão presentes, ou os sintomas podem resultar em prejuízo acentuado no funcionamento social ou profissional.

Fonte: DSM-VTM

Critérios subjetivos e de complexa observação, demandando um labor e processo avaliativo exaustivo a fim de eliminar qualquer outra hipótese que poderia elucidar as queixas direcionadas aos sujeitos problemas. Mas o que se percebe, hodiernamente, é um critério diagnóstico cada vez mais falho, desconsiderando pistas fundamentais no processo investigativo. Seria o afã de uma resposta que reafirma o cientificismo positivista? A realidade se duplica. Essa, que emerge de uma distorção da realidade, torna-se a base para novas comprovações científicas, igualmente distorcidas. A efetivação de um saber coaduna-se com arbitrariedades diversas e se estabelece uma nova verdade. Moyses e Collares (2011) criticam o processo da medicalização em massa que afeta crianças e adolescentes, principalmente no contexto educacional: 
Elabora-se uma hipótese sem qualquer evidência empírica que a suporte; convencidos de sua perfeição, cientistas passam a olhar a realidade sob o viés de sua crença; na busca de elementos que confirme sua hipótese inicial, deformam a própria realidade e essa realidade deformada é, por sua vez, a comprovação empírica da hipótese, conferindo-Ihe o estatuto de ciência. Transformada em verdade, atua ainda mais sobre a realidade, deformando-a mais e mais. As novas observações da realidade assim artificializada permitem modificações, evoluções na teoria, com explicações fisiopatológicas cada vez mais sofisticadas, complexas, atraentes. Cria-se uma espiral viciada, com novas máscaras para a mesma velha ideia que nunca se comprovou. (MOYSES; COLLARES, 2011, p. 92).

Alguns pesquisadores (Coutinho, 2007; Mattos, 2006; Andrade; Flores-Mendonza, 2010; Camargos, 2009) focam suas pesquisas partindo do pressuposto de que o TDAH é algo já definido de maneira consensual, sendo que a qualquer momento mudará de status de transtorno para doença. Argolo (2003), no seu artigo assertivo/diretivo, ao tratar do TDAH, que suscita tantos relativismos pregressamente mencionados, apresenta uma contradição de relevância: "O Transtorno do Déficit de Atenção com Hiperatividade (TDAH) é uma síndrome comum, mas controversa. Essa doença, que pode continuar por toda a vida [...]" (ARGOLO, 2003, p.197, grifo nosso). Essa precipitação, se não é apresentada de maneira explícita como ocorrera no artigo citado, acontece de maneira subliminar em diversos trabalhos. Há milhares de produções acadêmicas - desde a segunda metade da década de 80 do século XX- acerca do TDAH, a maioria partindo de uma equivocada premissa: é questão de tempo para a confirmação do TDAH, estudemos as maneiras de lidar com o fenômeno e as melhores drogas a serem utilizadas a fim de controlá-lo. De acordo com a Associação Brasileira do Déficit de Atenção (ABDA), o TDAH é "[...] um transtorno neurobiológico, de causas genéticas, que aparece na infância e frequentemente acompanha o indivíduo por toda a sua vida. Ele se caracteriza por sintomas de desatenção, inquietude e impulsividade". Mas há, de fato, a concordância em não ter conseguido identificar a região do cérebro afetada pelo transtorno, muito menos a identificação dos genes que estariam relacionados na manifestação dos mesmos (Rohde, 2004; Vasconcelos et al., 2005).

Rohde (2004) atenta para uma necessidade de relativizar o psicodiagnóstico, mas essa sensibilidade de atentar para os elementos psicossociais tem estado cada vez menos frequente.

A presença de sintomas de desatenção e/ou hiperatividade/impulsividade por curtos períodos (dois a três meses) que se iniciam claramente após um desencadeante psicossocial (por exemplo, a separação dos pais) deve alertar o clínico para a possibilidade de que a desatenção, a hiperatividade ou a impulsividade sejam mais sintomas do que parte de um quadro de TDAH. (ROHDE, 2004, p. 124).

E quando não é um desencadeante social? Será que há uma investigação mais apurada acerca dos elementos originários que culminaram em desatenção, hiperatividade, etc.? Será que esses 
minuciosos e necessários estudos a fim de averiguar possíveis causadores dos sintomas foram devidamente explorados?

O artigo do Paulo Mattos (2006) aborda o processo de validação, no Brasil, de um instrumento americano denominado MTA-SNAP-IV que serve para avaliar sintomas do TDAH e sintomas do Transtorno Desafiador e de Oposição (TDO). Esse é apenas um exemplo de diversas pesquisas realizadas a fim de validar instrumentais de natureza análoga. O que nos faz sentir a necessidade de maior criticidade acerca destes estudos, dentre outros motivos, é a maneira com que muitos são subsidiados por empresas farmacêuticas produtoras dos psicofármacos que combaterão os supostos transtornos.

Em Outubro de 1995, o órgão governamental encarregado de supervisionar e controlar medicamentos nos Estados Unidos da América - Drug Enforcement Administration (DEA), vinculado ao U.S Departament of Justice - alertou: grupos de apoio e consultoria têm um papel importante na circulação de informações sobre TDAH e seu tratamento. Nos anos recentes tem havido grande aumento na filiação a essas organizações e na participação em suas atividades. Children and Adults with Attention Deficit Disorder $(C H A D D)$ é a maior organização de suporte do país. CHADD tem um corpo de mais de 28.000 membros e tem 600 capítulos ao longo do país. [...] Recentemente tem chamado a atenção do DEA que a Ciba-Geigy (fabricante do produto à base de metilfenidato sob o nome comercial Ritalina $\Theta$ ) contribuiu com U\$ 748.000,00 para a CHADD, no período de 1991 a 1994. O DEA sabe que a profundidade da relação financeira com a empresa não é conhecida do público, incluindo membros da CHADD que nela têm se apoiado como guia para o diagnóstico e tratamento das suas crianças. [...] a relação entre a Ciba-Geigy e a CHADD levanta sérias dúvidas sobre os motivos da CHADD para seu proselitismo para o uso de ritalina. (U.S. Department of Justice, DEA apud MOYSES;COLLARES, 2011, p. 94-95).

As autoras alegam que esse modelo vicioso é reproduzido em diversos outros países, inclusive no Brasil.

Organizações não governamentais se constituem agregando pais de crianças e adolescentes rotulados, portadores do pretenso distúrbio e profissionais interessados em ajuda-los; geralmente as associações são presididas pela porção leiga; os profissionais compõem o quadro da diretoria e assessorias científicas, sempre em trabalho voluntário. [...] Publicações e teses, em especial no campo da neurologia e psiquiatria, insistem em divulgar o prejuízo causado aos pretensos pacientes e seus familiares pela exigência de prescrição da droga em receituários controlados. (ibid, p. 95).

O movimento de medicalização é tão poderoso que, mesmo com sérias contestações no que tange ao critério diagnóstico, até se realmente existem tais transtornos, há aumentos exponenciais de demanda, seja através do encaminhamento vide as próprias instituições de ensino, seja por 
uma iniciativa dos próprios pais a fim de buscar uma solução dinâmica e prática para os desafios emergentes representados pelos "comportamentos problemas" dos filhos.

Moyses e Collares (2011) questionam que,

[...] a transformação de parcela considerável dessa variabilidade-logicamente, os que têm mais dificuldades, seja em cognição, seja em comportamento - em uma pretensa doença neurológica, que jamais foi comprovada e é intensamente criticada no interior do próprio campo médico, muitas vezes tratada somente com intervenções pedagógica. Por que a necessidade de transformar a doença? A quem e a quê interessa? (p. 72).

Existe uma ideologia que subsidia o processo de medicalização. A ideologia do dinamismo, da resolutividade prática, do imediatismo. Características inerentes aos moldes da sociedade contemporânea e o sistema econômico vigente. No afã de alternativas práticas para a resolução de problemas complexos podem ocorrer inversões perigosas, colocando - por mais irônico que pareça - a saúde das crianças e adolescentes medicados em risco. Medicalizando e entorpecendo até mesmo a expressão e a sinalização dada pelos sujeitos de que há uma crise relacional impingindo ônus ao seu desenvolvimento pleno.

A sugestão medicamentosa, diferente da extrapolação que ocorre hodiernamente, deveria ser utilizada nas situações em que há uma desregulação biofisiológica apenas, e não quando subjaz uma "crise de conduta". Indubitavelmente seria uma forma salutar de empoderar crianças e adolescentes estigmatizados e cansados de serem encaminhados, do ir e vir, uma verdadeira peregrinação pelo sistema de saúde. Moyses e Collares (2011), em uma pesquisa realizada com professores imersos no processo de encaminhamento de crianças e adolescentes aos centros de saúde, constataram que

A história de escolarização de todas é traumática, com estigmatização sendo imposta logo no início. [...] Encaminhamentos, consultas, exames... Um processo repetido inúmeras vezes, em busca de um médico, um exame, até que se tenha um "diagnóstico". Até que se acalme o conflito provocado por um aluno que não aprende. Um processo avalizado, incentivado pelos profissionais de saúde. [...] E elas sofrem, incorporam a capacidade, a doença. Consideram-se pouco ou nada inteligentes porque não sabem ler. Têm medo de serem internadas, pois acreditam que para aprender a ler e escrever precisam ser hospitalizadas. Mas, não é uma doença? (MOYSES \& COLLARES, 2011, p.211).

O foco de grande contingente de cientistas e pesquisadores está no desenvolvimento de drogas a fim de dinamizar nossa vida. O biologicismo atrelado a um consenso medicalizante solapou o necessário pragmatismo casuístico; a necessidade de lidar com o fenômeno do fracasso escolar 
como multifatorial atentando para suas idiossincrasias. O consenso viria das repetições nos padrões que impediriam as crianças e adolescentes de exercer o pleno labor da alfabetização e do processo de escolarização em geral. A massificação dos psicofármacos se traduz em danosas consequências nas matrizes inter-relacionais. A pregressa comunicação tête-à-tête dá lugar à apresentação de laudos, culminando numa insensibilização generalizada.

\section{CONSIDERAÇÕES FINAIS}

Tratar de um tema tão amplo atrelado aos referenciais teóricos selecionados que subsidiaram minhas reflexões foi algo deveras instigante. Importante também recordar que a escolha do tema ocorreu de maneira natural e processual. A certeza de que o sistema educacional brasileiro é falho, subsidiado por ideologias geradoras de efeitos diversos: conformismo, monolitismo, sectarismo, etc. tendo como consequencia um crescimento exponencial de encaminhamentos de crianças e adolescentes a saberes terceirizados, produzindo rótulos e adjetivações estereotipadas, foi algo tocante, a força motriz necessária para a produção de um trabalho que servisse de alerta. As relações sociais estão sendo desconsideradas à medida que um cientificismo desmesurado surge como verdade inconteste; um delimitador de fronteiras.

A importância de se discutir a cultura da medicalização de crianças e adolescentes em âmbito escolar nesse contexto se justifica quando se constata uma alienação por parte da família, dos educadores, alunos e profissionais terceirizados. O relativismo e a minuciosa investigação dão lugar ao pragmatismo e dinamismo dos psicofármacos. As relações sociais, que constitui a unidade fundamental de uma sociedade, dão lugar a batuta do saber científico. A vida é naturalizada.

Ao longo do trabalho foi demonstrado que o atual cenário não surgiu de maneira abruptamente, e sim por relações construídas socialmente ao longo dos anos. Acompanhou-se o sutil movimento de uma ciência que viria justificar uma inquietante contradição: por que uma sociedade fundada nos princípios de liberdade, igualdade e fraternidade - oriunda da revolução francesa - têm a marca indelével da desigualdade social? Um cientificismo ingênuo engendrou as mais variadas arbitrariedades travestidas de teorias diversas e controversas: racistas, hereditárias e da carência cultural. E essas tentavam explicar, através de estudos contestáveis, o porquê da existência de tanta segregação. A culpabilização voltava-se para a cor da pele do sujeito, os atributos genéticos e as famílias desestruturadas. 
A investigação não se contentou em desvelar as ideologias fundantes dos fenômenos hodiernos. O quefazer de profissionais imersos no ciclo vicioso dos desmesurados psicodiagnósticos é tema notório e recorrente. Autores que nos ajudam a pensar de maneira construtivista, empoderando todos os elementos que compõem as instituições de ensino; impingindo força em estruturas de pensamentos e rotinas cristalizadas; permitindo a circulação de práticas e reflexões que vão de encontro à lógica da psicopatologização. Atentar para os discursos de um sujeito do suposto saber especializado e identificar contradições foi uma estratégia utilizada principalmente em se tratando dos autores aludidos que defendiam a utilização de psicofármacos, mas que não conseguiam entrar em consenso na simples tarefa de definição do fenômeno. O TDAH transformou-se - no dizer de alguns cientistas - em doença crônica. Mesmo sem provas materiais; uma tentativa de introjetar uma verdade a todo custo?

Destarte, me darei por satisfeito se esse trabalho produzir reflexões e desconfortos diversos. Ações éticas, humanas e sensíveis se mancomunam com um saudável preciosismo. $O$ preciosismo a favor da vida social.

\section{REFERÊNCIAS}

ASSOCIAÇÃO BRASILEIRA DO DÉFICIT DE ATENÇÃO (ABDA). O que é TDAH. Disponível em: <http://www.tdah.org.br/br/sobre-tdah/o-que-e-o-tdah.html>. Acesso em: 20 ago. 2017.

ABREU, Maria Helena do Rego. Medicalização da vida escolar. 2006. Dissertação (Mestrado em Educação) - Universidade Federal do Estado do Rio de Janeiro, Rio de Janeiro.

AMERICAN PSYCHIATRIC ASSOCIATION (APA). DSM-5 - Manual Diagnóstico e Estatístico de Transtornos Mentais. Porto Alegre: Artmed, 2014.

ANDRADE, Alana Concesso; FLORES-MENDOZA, Carmen. Transtorno do Déficit de Atenção/Hiperatividade: o que nos informa a investigação dimensional?. Estud. psicol. (Natal),

Natal, v. 15, n. 1, Apr. $2010 . \quad$ Disponível em $<$ http://www.scielo.br/scielo.php?script=sci_arttext\&pid=S1413-294X2010000100003

\&lng=en\&nrm=iso >. Acesso em: 29 jul. 2017.

ANGELUCCI, C. B. Por uma clínica da queixa escolar que não reproduza a lógica patologizante. In: SOUZA, B. P. Orientação à Queixa escolar. São Paulo: Casa do Psicólogo, 2007, p. 353-378. 
ARGOLLO, Nayara. Transtornos do déficit de atenção com hiperatividade: aspectos neurológicos. Psicol. Esc. Educ. (Impr.), Campinas, v. 7, n. 2, Dec. 2003. Disponível em http://www.scielo.br/scielo.php?script=sci_ arttext\&pid =S1413$85572003000200010 \&$ Ing=en\&nrm=iso >. Acesso em: 9 ago. 2017.

CAMARGOS JR., Walter; NICOLATO, Rodrigo. Características das prescrições no transtorno de déficit de atenção/hiperatividade. J. bras. psiquiatr., Rio de Janeiro, v. 58, n. 3, 2009 . Disponível em <http://www.scielo.br/scielo.php?script= sci_arttext\&pid=S0047$20852009000300009 \&$ Ing=en\&nrm=iso>. Acesso em: 16 ago. 2017.

COUTINHO, Gabriel. et al. Transtorno do déficit de atenção e hiperatividade: contribuição diagnóstica de avaliação computadorizada de atenção visual. Rev. psiquiatr. clín., São Paulo, v. 34, n. 5, 2007. Disponível em <http://www.scielo. br/scielo.php?script=sci_arttext\&pid=S010160832007000500003\&lng=en\&nrm=iso $>$ Acesso em: 11 ago. 2017.

GALLO, Foucault: (Re)pensar a Educação. In: RAGO, Margareth; VEIGA- NETO, Alfredo (Org.), Figuras de Foucault, 2. ed. Belo Horizonte: Autêntica, 2008. P253-260.

GALTON, F. Hereditary Genius: an inquiry into its laws and consequences. London: Macmillan/Fontana, 1869.

GARRIDO, J.; MOYSÉS, M. A. A. Um Panorama Nacional Dos Estudos Sobre A medicalização da aprendizagem de crianças em idade escolar. In: Conselho Regional de Psicologia de São Paulo (orgs.). 1.ed. Medicalização de crianças e adolescentes: conflitos silenciados pela redução de questões sociais a doenças de indivíduos, São Paulo: Casa do Psicólogo, 2011, p. 150-161.

MACHADO, A.M. Plantão institucional: um dispositivo criador. In: MARCONDES, A. FERNANDES, A.; ROCHA, M. Novos possíveis no encontro da psicologia com a educação. São Paulo: Casa do Psicólogo, 2007, P. 117-143.

MATTOS, Paulo. et al. Apresentação de uma versão em português para uso no Brasil do instrumento MTA-SNAP-IV de avaliação de sintomas de transtorno do déficit de atenção/hiperatividade e sintomas de transtorno desafiador e de oposição. Rev. psiquiatr. Rio Gd. Sul, Porto Alegre, v. 28, n. 3, dez. 2006 . Disponível em <http://www.scielo.br/scielo.php?script=sci_arttext\&pid=S0101-

$81082006000300008 \&$ Ing=en\&nrm=iso $>$. Acesso em: 18 ago. 2017.

MOYSES, M. A. A.; COLLARES, C. A. L.Dislexia e TDAH: Uma análise a partir da ciência médica. In: Conselho Regional de Psicologia de São Paulo (orgs.),1.ed., Medicalização de crianças e 
adolescentes: conflitos silenciados pela redução de questões sociais a doenças de indivíduos, São Paulo: Casa do Psicólogo, 2011a, p. 71-110.

MOYSES, M. A. A. ; COLLARES, C. A. L. Preconceitos no cotidiano escolar: a medicalização do processo ensino-aprendizagem. In: Conselho Regional de Psicologia de São Paulo (orgs.),1.ed., Medicalização de crianças e adolescentes: conflitos silenciados pela redução de questões sociais a doenças de indivíduos, São Paulo: Casa do Psicólogo, 2011b, p. 193-213.

PATTO, Maria Helena Souza. Para uma Crítica da Razão Psicométrica. Psicol. USP, São Paulo, v.8, n.1, 1997. Disponível em <http://www.scielo.br/scielo.php? script=sci_arttext\&pid=S010365641997000100004\&lng=en\&nrm=iso >. Acesso em: 15 ago. 2017.

PATTO, M. H. S. A produção do fracasso do escolar: histórias de submissão e rebeldia. 3. ed. São Paulo: Casa do Psicólogo. 2008.

POLIAKOV, Léon. O mito ariano: ensaio sobre as fontes do racismo e dos nacionalismos. Editora Perspectiva: Editora da Universidade de Sao Paulo, 1974.

RAGO, Margareth; VEIGA-NETO, Alfredo (Org.).Figuras de Foucault, 2. ed. - Belo Horizonte: Autêntica, 2008.

ROHDE, Luis Augusto. et al. Transtorno de déficit de atenção/hiperatividade na infância e na adolescência: considerações clínicas e terapêuticas. Rev. psiquiatr. clín. [online]. 2004, vol.31, n.3 [cited 2012-10-09], pp. 124-131. Disponível em: <http://www.scielo.br/scielo.php?script=sci_arttext\&pid=S0101-60832004000300 002\&lng=en\&nrm=iso >. Acesso em: 22 ago. 2017.

ROHDE, Luis Augusto. et al. Transtorno de déficit de atenção/hiperatividade. Rev. Bras. Psiquiatr., São Paulo, 2000. Disponível em <http://www.scielo.br/scielo. php?script=sci_arttext\&pid=S1516$44462000000600003 \& \operatorname{lng}=e n \& n r m=i s o>$. Acesso em: 12 ago. 2017. 